\section{NOTAS SOBRE LA PROSA PERIODÍSTICA DE CARMEN DE BURGOS}

\author{
Ricardo Senabre Sempere \\ Universidad de Salamanca \\ ricardo.senabre@gmail.com
}

\begin{abstract}
Like so many authors in the same period, Carmen de Burgos carried out the journalism and a purely literary creation at the same time. In these few pages it is tried to make a further analyze on the essential features of her prose which is erudite although focussing a large number of readers through written press. The most frequent composition structures whom the authoress preferred are taken into consideration in order to give a picture of the journalistic prose that characterizes her work.
\end{abstract}

KEY WORDS: Journalism; Burgos; Carmen de; analysis of the prose; correlations; metaphors.

Recogida sólo parcialmente en volúmenes, la obra periodistica de Carmen de Burgos aguarda un estudio detenido, que tendría que comenzar por ordenar y dar a conocer la inmensa cantidad de artículos desperdigados en periódicos y revistas del primer tercio del siglo XX. En la breve "Autobiografía" antepuesta al libro Al balcón (Valencia, F. Sempere, s. a. [1913]) declaraba la autora orgullosamente: "Colaboro en un centenar de periódicos". Acaso la cifra sea un tanto hiperbólica, pero, en cualquier caso, si puede comprobarse la continuidad y frecuencia de esa tarea periodística revisando algunas de las más conocidas publicaciones de la época: en Diario Universal, dirigido por Augusto Suárez de Figueroa, Carmen de Burgos se convirtió el 1 de enero de 1903 en la primera redactora de un periódico en España, firmando la columna diaria "Lecturas para la mujer" con el seudónimo de Colombine que la identificaría siempre, aunque en ocasiones utilizó algún otro; al mismo tiempo, comenzó su colaboración asidua con ABC (19031905); pero fue Heraldo de Madrid el diario al que perteneció siempre desde el otoño de 1905 hasta el final de su vida (1932); en paralelo, se sucedieron las colaboraciones en El Pueblo [Valencia] (1906-1907, con el seudónimo de "Gabriel Luna"), Revista Crítica (1908-1909; "la primera en tener una sección dedicada a los judíos", según aseveración de la autora y directora de la revista en la citada "Auto-

\section{NOTES ABOUT THE JOURNALISM PROSE BY CARMEN DE BURGOS}

RESUMEN: Como muchos autores de la época, Carmen de Burgos simultaneó el periodismo con la creación propiamente literaria. En estas páginas se intenta analizar cuáles son los rasgos esenciales de una prosa culta que, sin embargo, se dirige mediante la prensa a un público muy amplio. Se tienen en cuenta las estructuras compositivas más frecuentes, así como las creaciones metafóricas predilectas de la autora, a fin de dar una imagen de la prosa periodística que la caracteriza.

PALABRAS CLAVE: Periodismo; Burgos; Carmen de; análisis de la prosa; correlaciones; metáforas.

biografia"), Nuevo Mundo (1911-1930), La Esfera (19141930), 0 Mundo [Lisboa] (1919-1922), Revista de la Raza (1922-1930), Ondas (1927), y otras muchas publicaciones de dentro y fuera de España. Pero no se trata ahora de inventariar las pruebas que acrediten la asidua presencia de la autora en la prensa. El ingente acopio de datos llevado a cabo en su momento por Concepción Núñez Rey en un libro imprescindible (Carmen de Burgos, Colombine, en la edad de plata de la literatura española, Sevilla, Fundación J. Manuel Lara, 2005), punto de partida para cualquier acercamiento a la autora, nos exime de esa tarea. Sí conviene matizar algunos puntos acerca de la variadísima obra impresa de Carmen de Burgos. La mayor parte de los autores coetáneos frecuentaron asimismo los periódicos, y los ingresos obtenidos por estas colaboraciones complementaron decisivamente los que ya obtenían gracias a otros menesteres: la cátedra en Unamuno, Ortega o Antonio Machado, los contratos editoriales - por raquíticos que fueran- en Baroja o Valle-Inclán, las representaciones teatrales en Benavente, constituian los medios de vida de estos autores, de modo que el resultado económico de sus trabajos periodísticos es en ellos casi siempre de menor consideración que el hecho de disponer de una ventana abierta a miles de lectores y de un escaparate donde inscribir periódicamente su nombre, a manera de recordatorio permanente o fe de vida, sin 
duda con efectos, buscados o involuntarios, de carácter propagandístico.

Pero no es ésta la situación de Carmen de Burgos. La pretensión de vivir exclusivamente de la literatura o de las colaboraciones en la prensa era -hace un siglo más que ahora- algo que pocos escritores podian permitirse. Ejercer de lo que hoy llamariamos periodista freelance, subsistiendo a base de trabajos esporádicos, dependientes con frecuencia de amistades o relaciones cambiantes, obliga muchas veces a realizar tareas ajenas a la vocación y a la trayectoria personal. Una buena parte de los esfuerzos de Carmen de Burgos se volcó en menesteres de encargo -de pura subsistencia- que, si en ocasiones no están muy alejados del orbe literario, como sucede con los libros sobre Leopardi o Larra, e incluso en las traducciones de Renan, Ruskin o Tolstói -estos a través de la lengua francesa-, en otros no pasan de ser "arreglos" o adaptaciones de libros utilitarios: modelos de cartas, obras sobre jardinería, arreglos del hogar, salud y belleza, labores, cocina... Naturalmente, todo esto quedará al margen de cualquier consideración en las páginas que siguen.

Por otra parte, Carmen de Burgos se muestra sumamente versátil para adecuar su estilo a la índole del texto que compone. Los artículos que consisten, por ejemplo, en semblanzas divulgativas de personajes célebres -sobre todo mujeres, como corresponde a la ideología marcadamente feminista de la autora-, o bien en comentarios acerca de la actualidad política y social, parecen exigir una poda de artificios retóricos y la aplicación de un lenguaje directo, sin imágenes, denotativo y funcional. Destacan los datos, los argumentos, las propuestas, y no los elementos ornamentales, como acreditan muchos artículos aparecidos en el Heraldo de Madrid, o los publicados en El Pueblo, especialmente virulentos por su radicalismo político y anticlerical. En cambio, las crónicas de viajes, los artículos en que se describen lugares lejanos o costumbres exóticas, unidas con frecuencia a recuerdos literarios, a comentarios sobre artistas plásticos, libros 0 autores extranjeros, ofrecen un estilo mucho más cuidado, y desarrollan estructuras compositivas, a menudo complejas, que delatan la búsqueda de una prosa artística de tendencia barroca, repleta de paralelismos y enumeraciones que en otros casos, cuando la autora practica el estilo más funcional y a ras de tierra del periodismo, sólo se insinúa o no aparece en absoluto.

\section{ModALIDADES FRASEOLÓGICAS Y CORRELACIONES}

No obstante, incluso en aquellos artículos sin especiales pretensiones literarias se apuntan casi desde el comienzo tendencias ritmicas muy sostenidas. Así, Mme. Curie "analiza sin cansancio, observa con paciencia, examina con tenacidad" ( $A B C, 17-\mathrm{VII}-1906)$, frase trimembre con analogias entre sus miembros (verbo en tercera persona del presente, expansiones preposicionales en los tres casos) e incluso cierta gradación semántica entre los sustantivos paciencia y tenacidad. Con mayor simplicidad hallamos este otro ejemplo de estructura trimembre, ahora reforzada por la anáfora: "Todos los servicios, toda la organización, toda la dirección está en manos de las mujeres" (Heraldo de Madrid, 27-I-1917). Lo mismo sucede en: "Coimbra ejerce influencia en los espíritus con su ambiente, con su armonía, con sus proporciones" (La Esfera, 20-V-1922). 0 este caso de análoga disposición: "Llenó la mujer todas las páginas literarias, se mezcló en todas las fábulas, intervino en todos los conflictos" (Al balcón, p. 41). La rotundidad expresiva en un artículo polémico puede también reforzarse mediante la reiteración ternaria del mismo sintagma, como al afirmar que el catolicismo tradicional se dedicó a "proclamar como virtudes la destructora castidad, la envilecida pobreza y la humillante resignación" (El Pueblo, 14-X-1906), donde el uso exclusivo de núcleos léxicos de concordancia femenina y el mantenimiento del orden adjetivo+sustantivo proporcionan al texto un carácter solemne que refuerza su tono combativo. Cuando la estructura compositiva de la frase es binaria, se intenta su aprovechamiento para establecer paralelismos o antítesis: "Ese espectáculo [...] humilla y avergüenza a todas las mujeres y debe humillar y avergonzar a todos los hombres" (Heraldo de Madrid, 29-II-1916). El artificio es más evidente aún en esta sucesión de pares contrapuestos e inscritos en una estructura ternaria gobernada por la forma "se ve": "Se adivina el carácter de la persona, se ve si es franca o recelosa, leal o falsa, educada o grosera" (Al balcón, p. 70). En pasajes más complejos, las parejas antitéticas pueden organizarse en series que prolongan el sujeto con una construcción trimembre que las cierra: "Estas almas de mujer, frías en apariencia, complicadas a la vez, apasionadas y juiciosas, terribles y buenas, leales y pérfidas, engañosas y nobles, donde todo se amalgama, se confunde y se mezcla, no tienen punto de semejanza..." (Al balcón, p. 115). Obsérvese cómo las contraposiciones, que se inician de un modo titubeante -ya que la antí- 
tesis frías / complicadas resulta un tanto forzada-, van encaminándose hacia la antonimia (apasionadas / juiciosas, leales /pérfidas, etc.) hasta desembocar en la triada se amalgama, se confunde y se mezcla, que restaura la estructura desbordada por el apasionamiento discursivo anterior y la cierra mediante la conjunción copulativa. Las series plurimembres acaban siempre por desembocar en módulos binarios o ternarios que les devuelven su forma clásica y equilibrada -la que Colombine parece preferir-, o bien frenan su posible dispersión mediante anáforas y estructuras repetidas: "La Iglesia con su consentimiento, El Estado con su abandono, los dueños con su egoísmo y el pueblo con su indiferencia, todos han contribuido a esta expoliación de las obras de arte" (Al balcón, p. 217). La reiteración de las expansiones introducidas por "con su", unida a la fórmula resumidora todos, atenúa la extensión de la serie, subraya los apoyos ritmicos que segmentan el enunciado y proporciona al conjunto la solidez de un razonamiento discursivo bien fundado y de límites precisos. Muy pocas veces se abandona la autora a la enumeración libre y abierta, aunque hay algún caso en el que resuenan, atenuados, los ecos de la adjetivación romántica: "Son melopeas vagas, flotantes, indecisas, simples, monótonas" (Mis viajes por Europa: Suiza, Dinamarca, Suecia y Noruega [1914], Murcia, Nausicaa, 2006, p. 178). 0 se confía el cierre a una forma superlativa: "La multitud [...] paga el ser así con su propio sacrificio, volviéndose liviana, torpe, débil, deleznable, fugacísima" (Al balcón, p. 100).

No es arriesgado señalar los modelos estilísticos, porque la frecuencia de las estructuras trimembres es una caracteristica de la prosa surgida del Modernismo. Se hallan con profusión en las Sonatas de Valle-Inclán, en Azorín, en el primer Ortega y Gasset, como han puesto de relieve numerosos estudios ya clásicos sobre estos autores. Y también Colombine, lo mismo que aquellos maestros, se deja mecer en alguna ocasión por el vaivén de los metricismos y las asonancias internas: "[Las montañas son] comparables al mar por su belleza austera, su majestad y su grandiosidad severa" (Mis viajes, p. 207). En este aspecto, Carmen de Burgos no se aparta de la tendencia coetánea, aunque en su prosa no exista a priori una voluntad de estilo tan palmaria como la de los autores citados. Cuando ésta surge, los enunciados trimembres pueden repetirse y acumularse dentro de la misma frase, como en este pasaje en el que destacaré en cursiva las construcciones ternarias: "Al llegar a ella [la montaña] se pierde, se desvanece, se achica [...]
No hay nada, sino un desierto vulgar de nieblas, de hielos y de rocas, aunque, sin embargo, la vista distingue desde alli un nuevo panorama, otras planicies, otras siluetas, otras montañas" (Mis viajes, p. 210). 0 bien, con un enunciado menos extenso, pero más homogéneo y mejor trabado: "La venganza y los celos [...] son pasiones inmorales, pero grandes, bellas, humanas cuando las sienten los sanos, los fuertes, los seres llenos de vida" (Mis viajes, p. 101). Algunos ejemplos recogidos antes sugieren cómo, en los casos más cuidados de agrupaciones trimembres, parecen ofrecerse a todo escritor -también, naturalmente, a Colombine- dos posibilidades (no forzosamente excluyentes) que combinan sintaxis y semántica: o los elementos reiterados pertenecen a un mismo ámbito significativo 0 , además, se establece entre ellos cierta gradación expresiva. En el último pasaje citado, los adjetivos de la tríada primera (grandes, bellas y humanas) son de significado excesivamente vago para formar un conjunto homogéneo, pero la siguiente está constituida por elementos afines que se someten a una ordenación ascendente: de sanos se pasa a fuertes para rematar el escalonamiento con una fórmula que completa las anteriores y las subsume: los seres llenos de vida. Es como si se evocara el tránsito desde la niñez prometedora a la adolescencia pujante y la posterior plenitud.

Junto a estas construcciones, tienen menor interés y menor valor ciertas fórmulas anafóricas que ostentan demasiado visibles los latiguillos de la prosa oratoria: "Se escucha un rumor de viento, un rumor que nos sorprende" (Mis viajes, p. 80); o bien: "una mirada buena, una mirada que nos ofrece amistad" (Mis viajes, p. 80). Y, sin renunciar a las estructuras binarias: "Todos estos días ha hecho niebla, una niebla muy blanca y muy espesa" (Mis viajes, p. 211). Pero también hay usos afortunados de la anáfora. Al describir, en un artículo de viaje, la primera impresión que produce Suiza, lo más destacable es la presencia de la nieve. Pues bien: en el arranque del artículo, la palabra nieve aparece diez veces en poco más de doce líneas (Mis viajes, p. 9):

Una sábana de nieve cubre toda Suiza [...] ¡Nieve por todas partes! Un albor interminable. Los árboles están cubiertos de nieve, las casas parecen enterradas, las montañas envueltas en su caperuza blanca de la cima a la falda. Se siente el vértigo de la nieve, la obsesión de la blancura [...] Es tan aguda, tan punzante esta nieve, que deslumbra, alucina, se mete en el cerebro [...] Quisiéramos comer nieve, pisar nieve,

ARBOR CLXXXVI EXTRA JUNIO 2010 107-113 ISSN: 0210-1963 
bañarnos en nieve [...] Hay una voluptuosidad extraña en la blancura de la nieve...

Habria que añadir que estas modalidades discursivas, las más sujetas a cánones retóricos, aparecen también, como era de esperar, en las obras de ficción, más cercanas a la literatura y distantes del periodismo y el reportaje. En El hombre negro [La Novela Corta, n. ${ }^{2} 27,1916$ ] se habla de "la vida de paz, de unión, de compenetración con el marido" (p. 6), o del hijo como refugio "para todas esas mujeres desengañadas, brutalizadas, sin amor" (p. 12), y hay una referencia a "las manos largas, las manos ganchudas, las manos de garduña de su marido" (p. 18), donde la organización ternaria y anafórica se ve reforzada, además, por la gradación semántica de los adjetivos. En El perseguidor [La Novela Corta, 1917] -que narra la historia de una viuda andaluza que se traslada a Madrid y se dedica a viajar-, el personaje se deleita "oyendo las historias de bandidos, de hechos audaces, de crímenes" (p. 4). Ejemplos de esta naturaleza podrían espigarse sin dificultad en los relatos de la autora, y no sería tarea inútil estudiar la proximidad - o la distancia- entre esta prosa elaborada con intención literaria y la más funcional de los trabajos periodísticos.

\section{IMÁGENES NUCLEARES}

Carmen de Burgos no es una escritora especialmente inclinada al uso de la expresión traslaticia. Los símiles abundan más que las metáforas, y las imágenes utilizadas para comparar o para identificar forman un repertorio limitado, que contrasta con la caudalosa abundancia de Ramón Gómez de la Serna -por citar a un escritor cercano a Colombine- 0 a los ricos modelos de Ortega, tan influyentes desde muy pronto en la prensa más culta del siglo XX. Pero, precisamente por tratarse de un conjunto tan exiguo, resulta ilustrativo analizar los ámbitos a que pertenecen los elementos más frecuentes. Naturalmente, hay usos pálidos, que reproducen tópicos reconocibles, lo que sucede sobre todo en los escritos más radicales. Así ocurre con la vieja identificación entre las sotanas negras de los sacerdotes y las alas de los cuervos, presente en toda la literatura anticlerical del siglo XIX y que Carmen de Burgos no desdeña. En una ocasión se refiere a las "alimañas negras" y a los "grajos y pajarracos extraños que anidan bajo la enseña del Papa negro de los jesuitas o del Pontífice romano" (EI
Pueblo, 18-XI-1906). En otro momento se detiene la autora ante la escultura de un Cristo crucificado y sangriento situada en un pasadizo toledano: "Un farol se balancea lúgubremente ante él; las faldas negras de tanto eclesiástico dan la ilusión de los cuervos que preparan el festín a costa del reo inocente" (Al balcón, p. 227). Estas concesiones al lugar común, condicionadas tal vez por el medio en que brota el escrito y la naturaleza del público a que se dirige, no forman parte de la vertiente creativa mejor de la escritora. $Y$ tampoco ciertas imágenes que se repiten en artículos cercanos. Así, en un trabajo sobre Concepción Arenal: "Basta a la gloria de la inmortal pensadora la admiración de la posteridad, que hace brotar alrededor de su tumba las flores del agradecimiento" ( $A B C, 15-I X-1903)$. Y pocos meses más tarde, en un artículo acerca de otra mujer $-y$ acaso a este hecho se deba la reiteración de la fórmula-, la francesa Clemencia Royer, leemos: "iTriste condición del genio es adelantarse a su época para no ser comprendido, y que sólo sobre su tumba broten las flores de la admiración y el agradecimiento!" (ABC, 6-II-1904). Pero incluso al seleccionar usos desgastados puede notarse el esfuerzo de Colombine por repristinarlos, por introducir alguna variante que los separe del molde consabido. Un caso bastará para ejemplificar esta actitud. Si hablar de una piel "surcada de arrugas" es ya un tópico inerte, incompatible con cualquier escritura de pretensiones artísticas, existe una posibilidad de renovarla trayendo a la superficie del texto los elementos que se han ocultado siempre bajo la imagen del "surco". El resultado es éste: "La vejez ha hecho sarmentosas sus manos y ha marcado sus carnes con los surcos profundos de su arado" (Heraldo de Madrid, 10-XII-1916). La escritora no ha esquivado el tópico de las manos "sarmentosas", pero, al hacer explícita la imagen del "arado" de la vejez, ha inyectado en la antigua fórmula de los "surcos" de la piel una inesperada novedad.

Fuera de casos como estos, en que la autora se rinde ante el peso arrollador del lenguaje ya dado o, por el contrario, pugna con él, la originalidad existe, y radica en un homogéneo sistema imaginativo que trataremos de descubrir. Así, en una conferencia radiada en 1927 la autora se extendía -como en muchas ocasiones- en razonamientos acerca de las capacidades femeninas, comparándolas con las del hombre y centrándolas en su recepción de las informaciones radiofónicas, menos duraderas, al parecer, en la mente masculina (Ondas, número extraordinario, 19-VI-1927): 
Y así como para el hombre la audición es una cosa pasajera, la mujer va haciéndose un depósito de las músicas, los cantos, las enseñanzas y las ideas que oye, porque su espiritu, menos complicado y menos solicitado por cosas exteriores, está más dispuesto a almacenar. Ella recoge todo lo que oye, lo enhebra, lo pespuntea, lo borda y lo retiene.

Obsérvese que las imágenes seleccionadas para nombrar la actitud femenina de recibir las informaciones, organizarlas, interpretarlas y valorarlas, pertenecen al campo semántico de las labores de costura. Casi es inevitable recordar aquí a la Carmen de Burgos familiarizada con estas cuestiones, formada en el Magisterio de antaño y autora de libros como Moderno tratado de labores (Barcelona, 1904), si se desea entender cabalmente la espontaneidad de la creación metafórica. Y lo cierto es que este ámbito cercano y que casi podría calificarse de hogareño es el contexto en que nacen algunas de las imágenes más frecuentes de la escritora. Así ocurre con la sábana, que sirve como metáfora para designar la superficie extensa que cubre un terreno. Así, por ejemplo: "El vaporcito atraviesa la sábana de agua del gran Sund" (Mis viajes, p. 105). 0 bien, mediante el refuerzo de la sábana con nombres de telas: "El fiordo se ensancha en su sábana de agua rizada con un menudo oleaje, aguas de moaré y de crespón" (Mis viajes, p. 143). Como variante, la sábana puede aplicarse a una extensión de nieve: "Una sábana de nieve cubre toda Suiza" (Mis viajes, p. 9) o "la sábana de nieves que cubre toda su tierra" (id., p. 141). Secundariamente, adviértase que el uso de "sábana" convierte de manera implícita el lugar cubierto en un "lecho", lo que nos mantiene en el terreno de las imágenes familiares y domésticas elegido. $Y$ es posible todavía un paso adelante. En la naturaleza, la capa de nieve, convertida en "sábana", puede ser interpretada como un sudario: "Me parece que [las inscripciones] van a [...] retoñar en primavera, cuando la vuelta del sol derrita la nieve que durante los largos meses de invierno les sirve de sudario" (La Esfera, III, 106, 8-I-1916). De ahí se deriva, con expresión elíptica, la noción de "tumba", como cuando la escritora evoca "un país de nieve que enterraba su casa durante el invierno" (Mis viajes, p. 172).

Otro núcleo de imágenes de notable rendimiento es el que utiliza un grupo de variantes léxicas pertenecientes al ámbito de la costura y de ciertos elementos decorativos o embellecedores, una vez más -hay que insistir en ello- extraídos de la esfera doméstica. Se trata de la serie formada por los vocablos festón, cenefa, guirnalda y diadema, utilizados siempre con valor metafórico, como puede observarse en estos pasajes: "Se ha perdido hasta ese festón de algas doradas que señala en las rocas de las montañas de los fiordos el límite de las olas" (Mis viajes, p. 211). 0 bien, con una visión análoga: "Hay un festón de luces que señala el gran anfiteatro de su costa como un Zodíaco cuyos signos estuviesen escritos con luces" (La esfera, 13-X-1928). Con la variante léxica cenefa y con valor traslaticio semejante: "Absorta en contemplar la belleza de la ciudad partida por el cauce del Rhin, con su cenefa de ajomates en torno de sus cimientos y la poesía de sus casas ocultas entre sauces" (El perseguidor, p. 19). La "cenefa" o el "festón", con el significado genérico de "adorno situado en el borde de una prenda", puede aplicarse, como se ve, a la línea de luces que delimita la costa, a la franja de algas que señala el rompiente de las olas o a una hilera de flores, es producto de una visión que no sólo trata de embellecer la realidad observada, sino que intenta atraerla hacia un campo de connotaciones domésticas referidas a la costura y la indumentaria, como si Carmen de Burgos se dirigiera de un modo especial, consciente o inconscientemente, a un público de lectoras. Algo semejante cabe decir del uso metafórico de guirnalda, que aporta un carácter más marcadamente decorativo pero que, en realidad, se comporta como variante estilística de "festón" o "cenefa", como acreditan los ejemplos. Compárese el "festón de luces" citado antes con la "guirnalda de luces en semicírculo que dibujaban el Golfo" (El perseguidor, 17). Como "línea de edificios o ciudades" encontramos: "El lago tiene las aguas azules [...] Sus orillas ofrecen una guirnalda de ciudades alegres y pintorescas" (Mis viajes, p. 50). 0 bien: "Más lejos, el teatro de la Ópera y la guirnalda de palacios que forman el Strandvagen" (Mis viajes, p. 114). Y todo esto vale también para la voz diadema, que completa la serie de usos imaginativos referidas a la misma realidad: "Se ve toda la ciudad con [...] su cadena de islitas formando una diadema a su entrada" (Mis viajes, p. 152).

Otro grupo de imágenes se refiere a las nociones "sol" y "luna", y está constituido por las palabras hostia, disco o rueda de limón, que en ocasiones se mezclan en el mismo enunciado, como puede verse en este pasaje: "El disco rojo [del sol] se eleva con solemnidad de hostia. Remonta majestuosamente por este cielo cambiante [...] He recibido la comunión de esa santa hostia de fuego..." (Mis viajes, p. 214). Con referencia en segunda persona a la luna: "Quizá por 
eso es tan pura tu luz, pálida hostia de oro del Sil" (Revista Crítica, I, 1, septiembre 1908). El uso de la imagen hostia, aunque aparezca asociada a otras y momentáneamente referida a ellas, suele conducir, como ya se ha visto en el primer ejemplo citado, a la evocación de un rito religioso. Así, en la preparación del té "tiene algo de hostia la rueda de limón amarilla y transparente que cae en el vaso. Hay que coger este vaso como lo cogen los árabes y elevarlo con respeto para la consumación" (Mis viajes, p. 107). De la luna suele destacarse su luz pálida, razón por la que, en lugar de ser roja, como el sol, es plateada: "La luna ha dejado caer su disco de plata detrás de la siniestra cumbre del Gurugú" (Al balcón, p. 189). Y la imagen predilecta para compararla es la rueda de limón: "Una luna incolora, deslucida, de papel transparente, semejante a media rueda de limón" (Mis viajes, p. 160), fórmula aprovechada también en obras literarias: "Era ya de noche; una luna pálida y amarilla como una raja de limón brillaba en el cielo ceniza" (El perseguidor, p. 29). Incluso cuando las referencias al sol o la luna recurren a otras imágenes, no se renuncia a las habituales. El sol puede ser una dalia, pero no deja de ser un disco: "El sol se asemeja a una gran dalia doble, de una luz tan fría que deja mirar su disco rojo [...] se le ve como deshojarse en la lejanía dejando caer los pétalos uno a uno en el seno claro de Malaren" (Mis viajes, p. 115).

\section{Otros usOS METAFÓRICOS}

Aunque en menor proporción, existen otros campos imaginativos de cierto rendimiento que convendrá señalar someramente. Se trata de hallazgos expresivos que parecen propios, sobre todo, de la primera etapa de la escritora y que no suelen tener continuidad. Así, la idea de las ofrendas, el incienso, los exvotos que representan símbolos de gratitud y homenaje en determinados ritos de naturaleza religiosa, aparece con frecuencia, previa traslación metafórica, en los escritos de Colombine, habitualmente construidos en el interior de construcciones comparativas. Algunos ejemplos darán idea de la predilección por estas fórmulas. Aventurando el futuro, la escritora asegura que los aplausos que se prodigan a una figura como la de Mme Curie "llegarán hasta las serenas regiones donde ha trabajado, como el incienso que sube en oleadas de perfume ante el altar de los dioses" (ABC, 17-VII-1903). Acentuando mediante el subjuntivo el matiz de símil y separándose de la identificación metafórica, encontramos un pasaje todavía excesivamente verboso: "El tren se lanzaba rugiendo en busca de lejanos horizontes, alzando su penacho de humo como si quisiera incensar los aires y llevar a los cielos aquel vapor ceniciento, prueba del fecundo trabajo que redime a los pueblos y a las razas" (ABC, 14-VIII-1903). Una variante del incienso, pero con idéntico valor, son los exvotos que hallamos entre los elogios dedicados al juez francés Magneaud: "En el sencillo gabinete del Buen Juez se encuentran las cartas, los periódicos, los libros y las fotografías que llegan de todas partes del mundo como exvotos ofrecidos en el altar de un hombre que representa a la Humanidad y a la Justicia unidos [sic] en hermoso consorcio" ( $A B C, 27-X-1903)$. Y de los escritos más combativos de la autora cabe extraer alguna imagen que aprovecha un uso de origen caballeresco. Si azotar el rostro de alguien con el guante era, en un código bien conocido, expresión de la máxima ofensa, Carmen de Burgos intensifica con acierto el gesto al señalar cómo "aún la manopla de hierro del feudalismo azota el rostro de la sociedad moderna" ( $A B C, 27-X-1903)$ o al reclamar como algo indispensable, en un escrito tres años posterior, "abolir esta vergonzosa pena [de muerte] que aún deshonra nuestros códigos como la manopla de hierro del feudalismo que azota el rostro de la sociedad actual" (EI Pueblo, 13-XI1906). Y no hay que olvidar la esporádica aparición de ciertas imágenes que expresan relaciones afectivas y familiares, y que recuerdan algunas de las preferencias metafóricas de Unamuno, donde los lugares y los elementos del paisaje se vivifican sin cesar mediante relaciones maternofiliales. De acuerdo con este planteamiento, en Rodalquilar, lugar natal de la autora, "los cerros de rica entraña ofrecen la sonrisa del vallecito dormido entre las rocas abruptas" (Al balcón, p. 162), y "el mar se tendía dormido con su calma blanda en brazos de la playa" (id., p. 164).

Como ha podido advertirse, los usos metafóricos son en la prosa periodística de Colombine -el análisis de la prosa literaria obligaría a matizar esta aseveración- muy simples y casi traducibles miembro a miembro. Pero en alguna contada ocasión es posible encontrar construcciones complejas e ingeniosas, donde el desarrollo de una imagen inicial provoca la aparición de una serie metafórica con inserciones diversas cercana a la alegoría. Es en casos como éstos cuando se le antoja al lector percibir el eco de Ramón Gómez de la Serna, tan diluido, por lo general, en la obra de la escritora. Ramoniano es, en efecto, este pasaje que conviene citar por extenso (Mis viajes, pp. 109-110): 
Las botas que aparecen de noche delante de las puertas [de las habitaciones del hotel] son como la gran pizarra del hall que indica los habitantes de cada cuarto. Se sabe en dónde hay caballeros y señoras solas, o en dónde duerme una pareja o un niño. Están allí las botas como vigilantes para que no nos equivoquemos. Unas echadas, como perrillos que se acuestan, otras de pie, dispuestas a emprender la marcha. Algunas veces la una pisa a la otra como si le hiciese una seña. $Y$ las botas de matrimonios unas veces están amorosamente mezcladas y otras parecen dispuestas a seguir caminos contrarios.

$Y$, puesto que nos hallamos ante un posible contagio literario -0, al menos, ante una segura afinidad-, no estará de más recordar algún caso de prosopopeya del que podría afirmarse lo mismo, como un pasaje nacido de un viaje a Suiza en el que la visión de la autora hace de dos ríos una pareja de seres humanos (Mis viajes, p. 19):

Como prolongando el lago [Leman] se extiende la belleza del río. Un poco más allá el Ródano celebra sus bodas con el Arve. Es un espectáculo grandioso. Se ve llegar al Ródano con rapidez de flecha, él es el varón. Va desdeñoso, apresurado, descontento de la entrega que se le va a hacer. El Arve es la desposada; viene tímido, perezoso, a desposarse con él. Se les ve impulsados por una fuerza fatal; de tener voluntad cambiarían su cauce. No se aman. Cuando sus aguas caen en el mismo lecho corren aún durante muchos centenares de metros sin que se confundan las ondas azules del Ródano con las ondas grises del Arve. Al fin se fusionan, se confunden, se mezclan, para seguir juntos su camino rocoso y salvaje realizando el destino común de sembrar vida a su paso.

Pues bien: esta sostenida imagen que podríamos calificar de conyugal ha sido tal vez estimulada por el recuerdo difuso de otro pasaje en el que se anticipaba una visión análoga. En la novela de Galdós El 19 de marzo y el 2 de mayo, perteneciente a la primera serie de los Episodios $\mathrm{Na}$ cionales, cuenta Gabriel Araceli, que ha conseguido trabajo en una imprenta, cómo acude los domingos a Aranjuez para visitar a su amada Inés, que vive allí con su tío, el sacerdote Ceferino Santos. Almuerzan los tres y dan un paseo que acaba siempre de igual modo:
Por último, nos sentamos a orillas del río, y en el sitio en que el Tajo y el Jarama, encontrándose de improviso, y cuando seguramente el uno no tenía noticias de la existencia del otro, se abrazan y confunden sus aguas en una sola corriente, haciendo de dos vidas una sola.

Es evidente que la visión de los dos ríos que "se abrazan y confunden sus aguas" traduce el pensamiento y los deseos de Araceli, como él mismo confiesa a continuación: "Tan exacta imagen de nosotros mismos no puede menos de ocurrírsele a Inés al mismo tiempo que a mí". Se trata, en efecto, de un paisaje interiorizado, cuya visión está condicionada por el estado de ánimo del personaje, como corresponde a un relato novelesco. No es, por tanto, el caso de Carmen de Burgos, que en este caso, se mueve en el terreno del reportaje periodístico -0, si se prefiere, del libro de viajes- y no tiene que caracterizar a ningún personaje de ficción. Pero parece más que probable que en la construcción metafórica de Colombine haya operado el recuerdo de la página galdosiana, de igual modo que, muchos años después, esta página se proyectará sobre un pasaje de Unamuno (El artículo "Cuenca ibérica", publicado en EI Sol, 26-XI-1931) en que el rector de Salamanca describe el encuentro de los ríos Júcar y Huécar:

Se abrazan y conjugan Júcar y Huécar al pie de la iglesia mayor que ha bendecido tantos desemboques mutuos de vidas de almas oscuras [...] y a morir se han ido, mejidos sus caudales, vidas aparejadas en costumbre. Se conocieron acaso en aquel parque provinciano, enjaulado, y formaron un hogar.

Aquí, las coincidencias léxicas no dejan lugar a dudas. La literatura se nutre con frecuencia de literatura. La sombra alargada y frondosa de Galdós Ilega hasta Unamuno. Entre ambas figuras, Carmen de Burgos ha sabido inscribir una mirada personal, en la que tal vez haya ecos de experiencias íntimas, muy distintas de las esperanzadas reflexiones que gobernaban la mirada de Gabriel Araceli. Esta transformación de elementos dados, y también este acomodo de lo ajeno a lo propio para lograr la inserción de la vida en la literatura, son signos inequívocos del escritor auténtico.

Recibido: 14 de mayo de 2010

Aceptado: 7 de junio de 2010 